\title{
Salivary Gland Monomorphic Adenoma
}

National Cancer Institute

\section{Source}

National Cancer Institute. Salivary Gland Monomorphic Adenoma. NCI Thesaurus. Code C3686.

A benign epithelial neoplasm arising from the salivary glands. It is characterized by the presence of a monomorphic cellular infiltrate. 